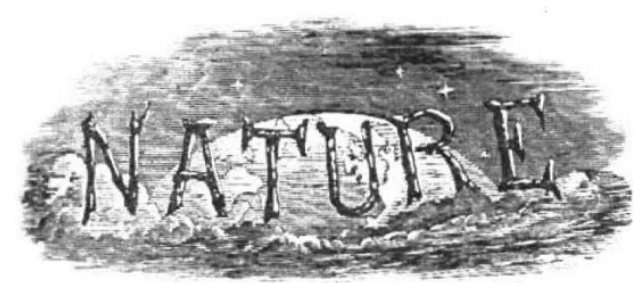

SATURDAY, DECEMBER 8, 1923.

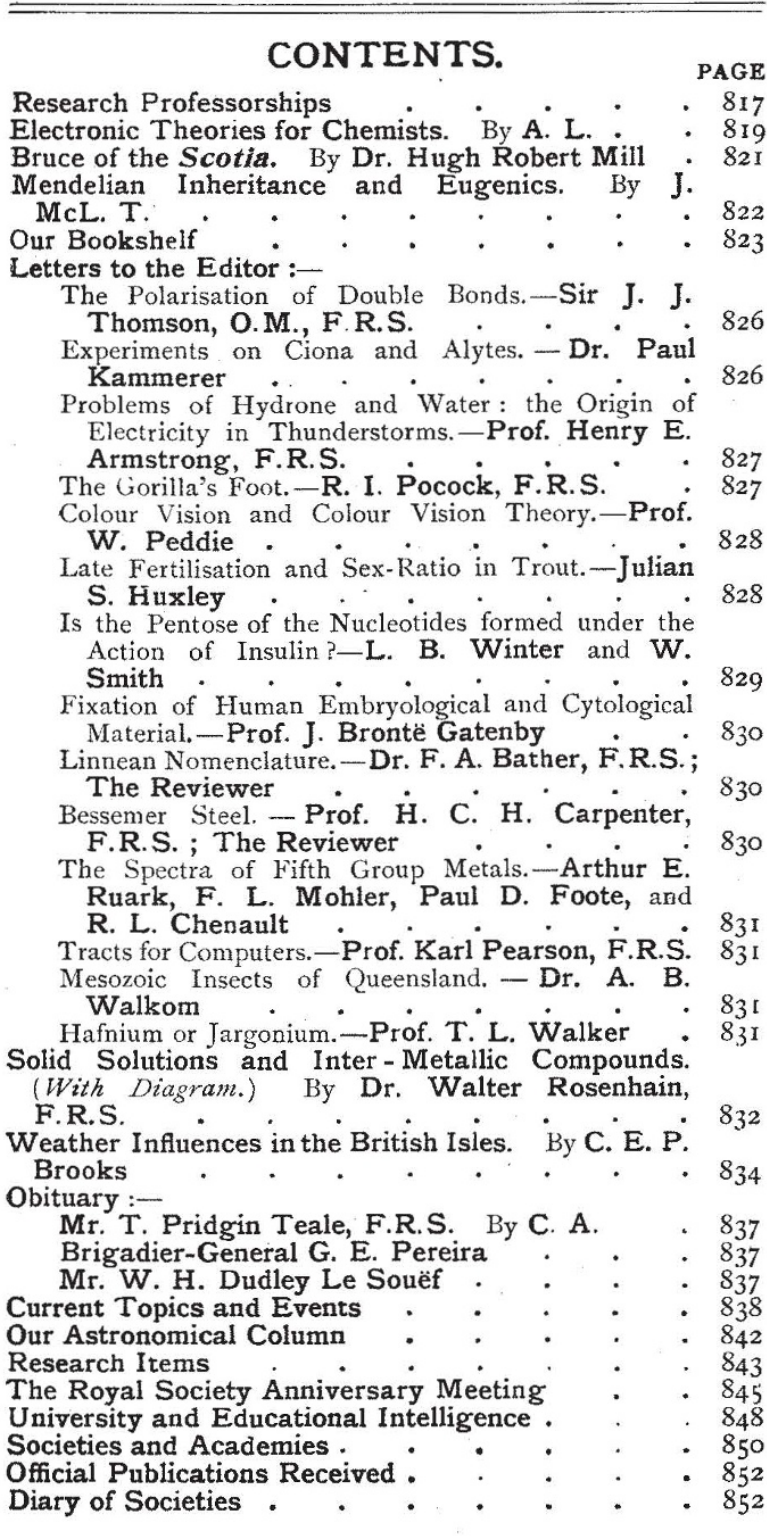

Editorial and Pubtishing Offices:

MACMILLAN \& CO., LTD.,

ST. MARTIN'S STREET LONDON, W.C.2.

Telegraphic Address: PHUSIS, LONDON.

Telephone Number: GERRARD 8830.

\section{Research Professorships.}

THIS year's anniversary meeting of the Royal Society, an account of which is given elsewhere in the present issue of Nature, was the first since Sir Alfred Yarrow made his munificent gift of $100,000 l$. to the Society in February last, " to mark my sense of the value of research to the community." The meeting was, therefore, appropriately devoted in the main to an account by the president, Sir Charles Sherrington, of the purposes to which this and other large benefactions are to be used. The essential aim of the Society is the creation of new knowledge by scientific inquiry, and the new professorships which have been founded through recent gifts will promote and facilitate this intention.

Lord Justice Warrington, in proposing the toast of the Royal Society at the anniversary dinner at the Hotel Victoria, drew a parallel between the proceedings in a court of law and those in a laboratory of science. In both cases evidence is elicited with the object of arriving at a correct judgment upon it, and endeavours are made by cross-examination to test the truth of the testimony given. The suggestion that it is much easier to get truthful response by appropriate stimulus in Nature than it is from human witnesses is, however, one to which scientific investigators may hesitate to subscribe. Nature can never be trusted to give a direct answer to a question if she can avoid it, and will deceive the inquirer if she can. Also, while the laws of civil life can be broken, there must be no exception to a law of Nature, which is simply a description of certain relationships expressed in words or in mathematical terms. When observations prove such a relationship to be incorrect, then the law has to be modified or abandoned to take the new facts into consideration. Moreover, while in civil law precedent is all-powerful, in science it counts, or should count, for nothing.

The motto of the Royal Society, Nullius in verba, adapted from Horace's Nullius addictus iurare in verba magistra-not bound to swear to the words of any master-is an expression of the revolt against authority which was in the ascendant when the Society was founded. Long before the reaction against the Aristotelian method and doctrine which Francis Bacon represented with such virulence and bitterness, Roger Bacon had claimed for himself and his contemporaries the liberty of independent inquiry. At the Renaissance, impatience with the constant appeal to the authority of Aristotle was widespread among all who were foremost in the revival either of science or of letters, and what Francis Bacon did in his "Novum Organum" 
was to embody prevailing views and propound a new philosophy.

In his "New Atlantis," Bacon planned a palace of invention, a great temple of science, where the pursuit of natural knowledge in all its branches was to be organised on principles of the highest efficiency. His Solomon's House was regarded as a prophetic scheme of the Royal Society, and the story of it as a vision of the practical results to be anticipated from diligent and systematic study of Nature. By the establishment of research professorships the Society is directly creating a body of experimenters on this design, which was that originally conceived for it, in addition to being " the Store-House of Natural Philosophy."

When a research professor is already associated with a university or other teaching institution, the appointment will mean that the professor will be relieved of his lectures and other duties of instruction of students. The amount of time which this work and participation in administrative affairs demand differs in different centres, but in most cases it leaves little opportunity for sustained attention to research problems. Prof. Alfred Fowler, who has been appointed to one of the Yarrow research fellowships, is professor of astrophysics at the Imperial College of Science and Technology, London; and though he has not perhaps been so overwhelmed with instructional responsibilities as are many professors in provincial universities, yet much of his time has had to be given to them, and the time left for his experimental investigations has been correspondingly limited.

Prof. Fowler's main contributions to astronomical physics are described in Sir Charles Sherrington's presidential address. The modern phase of his work may be said to have begun in the year 1912, when he succeeded in obtaining, from a tube containing helium and hydrogen, certain series of lines, some of which had previously been observed only in the spectra of a few stars or had been predicted on theoretical grounds as forming part of the spectrum of hydrogen. Shortly afterwards, Bohr published his now famous theory of the origin of spectra, in the light of which the series detected by Fowler were seen to be due to helium, and with this discovery began the close association between the experimental work of Fowler and the theoretical work of Bohr which has led to such remarkable advances in recent years.

In the Bakerian Lecture of $x_{914}$, Fowler showed that the enhanced lines of the alkaline earth metals formed series precisely similar to those of the "arc" lines, except that the series constant had four times its normal value. According to Bohr's theory, this meant that the enhanced lines were produced by atoms which had lost one electron, and the generalisa- tion at once followed that the atoms of any element which had lost one electron would yield series having $4 \mathrm{~N}$ in place of the Rydberg constant, N. Carrying the process still further, Fowler has recently shown that the spectrum of silicon contains series characterised by a constant $I 6 \mathrm{~N}$, indicating the existence of radiating atoms which have lost three electrons.

A great deal of Prof. Fowler's time has been devoted to the training of research students, whose work testifies to the encouragement and help they have received from him. Curtis's determination of the Rydberg constant for hydrogen, and Catalan's remarkable paper on the spectrum of manganese, may be mentioned as two of many examples of work of this kind. It is a matter for regret that his new appointment entails the cessation of the very clear and interesting courses of lectures from which students of the Royal College of Science have benefited for more than twenty years, but there is no doubt that the gain to science resulting from his larger opportunities for research work will be immense.

Major Taylor has not occupied a professorial chair, but he is lecturer in mathematics at Trinity College, Cambridge, and will continue his work there as Prof. Fowler will at the Royal College of Science. The new professors may take part in instruction, or not, but no work of this kind is to be undertaken if it should prevent them from giving the best of their energies to research. The holders of the Yarrow research professorships are to devote their whole time to research in mathematical, physical, chemical, or engineering science. The professorships are similar to the Foulerton medical research professorship of $\mathbf{I} 400 \mathrm{l}$. or more per annum, and may be compared with the Foulerton medical research studentship of $700 l$. per annum, the Sorby research fellowship of $600 l$. per annum, and the Beit memorial senior medical research fellowships of $600 l$. per annum. Particulars of these are given in the Yearbook of the Universities of the Empire (Appendix XXIV.). It may be of interest in connexion with these endowments to mention that there are a few similar foundations in the United States, notably the Heckscher Research Foundation, established in I 920 in Cornell University. "As research in America," said the founder, "suffers from the exhaustion of professors by teaching and other duties, it is my desire that professors and instructors . . . shall ... . for such periods of time as the university authorities may prescribe, be liberated partially or wholly from those duties," etc.; for the present the income is not to be used for permanent research professorships. Senator Vilas likewise bequeathed to the University of Wisconsin money for creating ten chairs of pure research without routine work, in which the salaries (Io,ooo dollars) would attract 
men of worth. The experiences of Johns Hopkins and Clark Universities, both of which were intended to be institutions for original scientific research, have shown the great difficulties that stand in the way of establishing independently of the state a university which shall be exclusively a school of advanced studies.

In Canada, Queen's University of Kingston, Ontario, has a Chown science research chair (in physics or chemistry), which was recently vacated by Dr. A. L. Hughes on his acceptance of a chair of physics in the University of Washington, St. Louis; and in connexion with the University of Alberta two " research professors" have been employed under the direction of an Industrial Research Council, of which the Premier of the Province was chairman, their fields of investigation being fuels and road materials. In Australia, the University of Queensland has lately established a research professorship of medical psychology.

In deciding that for the present the income is not to be used for permanent research professorships, the Heckscher trustees may have been influenced by criticisms which have been directed against the Carnegie Institution of Washington on account of their heavy budget for permanent establishments, which seems not altogether consistent with the original idea of the founder-to discover exceptionally endowed men in various specialities and give them for the time being the broadest facilities for accomplishing more or less definite pieces of work. It is their immunity from the risk of becoming overweighted with fixed establishment charges that contributes so largely to the success of foundations like the Mellon Institute, where research is organised on a " job " or contract system, the problem being set by a person or firm interested in its solution, the scientific worker being found and engaged, ad hoc, by the Institute, and a "fellowship". being assigned for a definite period fixed with reference to the probable duration of the research; in many cases the fellow is promised a "bonus" (which has in some cases reached ro,000 dollars) or a percentage on the industrial exploitation of the process studied.

All these research foundations differ, however, from those now established by the Royal Society inasmuch as they are associated with particular institutions. In the Society's scheme, there is perfect freedom as to the place of research, and the main intention is to give an investigator of proved worth the means to continue his explorations of the field of Nature undisturbed by other duties, and with his eye always towards the light. We welcome the generous recognition thus given to research as a profession, and believe that the action described by Sir Charles Sherrington marks the beginning of an important epoch in the history of the Royal Society.

$$
\text { NO. } 2823 \text {, VOL. I I } 2]
$$

\section{Electronic Theories for Chemists.}

(I) The Electron in Chemistry: being Five Lectures delivered at the Franklin Institute, Philadelphia. By Sir J. J. Thomson. Pp. v+ I44. (Philadelphia : The Franklin Institute, 1923.) r.75 dollars.

(2) Valence, and the Structure of Atoms and Molecules. By Prof. G. N. Lewis. (American Chemical Society Monograph Series.) Pp. r72. (New York: The Chemical Catalog Co., Inc., I923.) 3 dollars.

(I) SIR JOSEPH THOMSON'S book contains the $D$ substance of five lectures which were delivered so recently as April of the present year. The reviewer believes that it was dedicated to chemists and has read it in that light, for in no other can he pretend to see.

As is well known, the author does not subscribe to all the newer physical doctrines and is hopeful of founding a theory of the atom with the aid of less revolutionary postulates. Starting from the conception of the atom as a massive, positively electrified centre surrounded by electrons, Sir Joseph Thomson begins by admitting that the properties of the atom require the introduction of some principle not recognised in the older physics. This principle he supposes to affect the law of force between the nucleus of the atom and the electrons in such a way that at a certain distance the force changes from attraction to repulsion. The introduction of a new term into the expression of the usual inverse square law gives the required result, albeit somewhat indifferently well, and the corresponding stability of various electrically neutral systems composed of electrons, apparently stationary, can be worked out. The now familiar octet emerges naturally enough from such considerations, but the origin of the pair of electrons which form the "shell " of the helium atom and the $\mathrm{K}$ layer of heavier elements is left obscure, nor is it at once evident why the octets of the inert gases are relatively so extremely stable.

If no more than an adumbration of the periodic system is to be seen in the somewhat tentative theory which the author here proposes, this fact should not be allowed to weigh too heavily against it, lest hereafter it may prove that other theories have sacrificed too much in order to retain a predetermined outward form.

In chapter ii. the combination of atoms by means of one, two, or more electrons is considered, and it is explained why lithium, beryllium, boron, and carbon are solids whilst oxygen, fluorine, and neon are gases, and why, for example, the study of the mode of scattering of polarised light by gases furnishes evidence that the molecule of oxygen is more elongated than that of, say, hydrogen. Careful readers, however, will note that nitrogen does not fit into the picture, and will 